Anais da 3a Semana de Engenharia Civil da Universidade Federal do Sul e Sudeste do Pará Jan 2020 - v. 2 - n.1

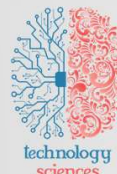

ISSN: 2674-6425

This article is also available online at: www.sapientiae.com.br

\title{
Escritório modelo de engenharia civil: relato de experiência na Amazônia oriental
}

Este artigo sintetiza o relato de experiência da implantação de um Escritório Modelo de Engenharia Civil em uma universidade no interior da Amazônia. Os fluxos migratórios incentivados por políticas públicas, como também, os espontâneos, dentre várias consequências positivas e negativas para as urbes amazônidas, acarretaram em um uso e ocupação do solo desordenado e com elevados índices de autoconstruções e habitações precárias na região. Nesse sentido, os Escritório Modelos de Engenharia se apresentam como uma possibilidade de fornecer serviços técnicos especializados, para populações com hipossuficiência econômica, por meio dos recursos técnicos e científicos disponíveis nas Universidades. Além disso, a prática desenvolvida pelos discentes participantes de um Escritório Modelo, pode configurar o exercício de aprendizagem com método ativo, conforme solicita as Diretrizes para os cursos de Engenharia, aprovadas em 2019. Com base no relato de experiência, esse artigo apresenta a possibilidade de o Escritório Modelo figurar como uma ferramenta que permita institucionalizar a aprendizagem baseada em projetos, que é um método ativo de aprendizagem, em um curso de Engenharia Civil. Através da técnica de grupo focal de análise sintetizando as informações por meio de método etnográfico, é possível confirmar a hipótese de o Escritório Modelo figurar como meio condutor para a implantação de metodologias ativas de aprendizagem, sendo um recurso adicional para o ensino de temas transversais no curso de Engenharia Civil, como Educação Ambiental, Cidadania, Gênero e Diversidade, Acessibilidade e Direitos Humanos.

Palavras-chave: Escritório Modelo; Temas Transversais; Educação em Engenharia; Método Ativo.

\section{Civil engineering model office: experience report on the eastern Amazon}

This article summarizes the experience report of the implementation of a Model Civil Engineering Office in a university in the interior of the Amazon. The migratory flows encouraged by public policies, as well as the spontaneous ones, among several positive and negative consequences for the Amazonian cities, resulted in a disordered use and occupation of the soil and with high rates of self-construction and precarious housing in the region. In this sense, the Engineering Model Offices are presented as a possibility to provide specialized technical services to economically underfunded populations through the technical and scientific resources available at the Universities. In addition, the practice developed by students participating in a Model Office may configure the active method learning exercise, as required by the Engineering Course Guidelines, adopted in 2019. Based on experience report, this article presents the possibility The Model Office is a tool for institutionalizing project-based learning, which is an active learning method, in a Civil Engineering course. Through the focus group analysis technique, synthesizing the information through an ethnographic method, it is possible to confirm the hypothesis that the Model Office is a guiding means for the implementation of active learning methodologies, being an additional resource for teaching Cross-sectional Themes. in Civil Engineering, such as Environmental Education, Citizenship, Gender and Diversity, Accessibility and Human Rights.

Keywords: Model office; Cross-sectional Themes; Engineering education; Active Learning.

Topic: Engenharia Civil

Reviewed anonymously in the process of blind peer.
Received: $12 / 11 / 2019$

Approved: 29/12/2019
Antonio Carlos Santos do Nascimento Passos de Oliveira (it) Universidade Federal do Sul e Sudeste do Pará, Brasil http://lattes.cnpq.br/6722503859790070

http://orcid.org/0000-0001-8284-0801

tonydarkgeol@gmail.com

\section{Referencing this:}

OLIVEIRA, A. C. S. N. P.. Escritório modelo de engenharia civil: relato de experiência na Amazônia oriental. Technology Science, v.2, n.1 p.13-17, 2020. DOI: http://doi.org/10.6008/CBPC2674$\underline{6425.2020 .001 .0002}$ 


\section{INTRODUÇÃO}

As urbes amazônidas passaram por diversos ciclos econômicos (BECKER, 2013) que, dentre várias consequências, das negativas, podem ser citadas a fragmentação espacial da malha urbana dessas cidades, e os diversos problemas habitacionais associados a isso (BIBAS et al., 2016). Nesse sentido, nas cidades proliferam habitações precárias em aglomerados subnormais (FEITOSA et al., 2016), e os Escritórios Modelos podem vir a contribuir para auxiliar na construção de alternativas para esse dilema social. Para que os discentes possam exercer uma aprendizagem por meio de um método ativo, como o Project Based Learning (PBL), os projetos podem, por ventura, serem hipotético, contudo, se existe essa demanda latente, por serviços técnicos especializados de Engenharia Civil, e as premissas legais da lei federal 11.888, de 24 de dezembro de 2008, articulam essa possibilidade, então é salutar que esse serviço seja fornecido a essa população.

A lei federal 11.888, de 24 de dezembro de 2008, tem como premissa que famílias consideradas como portadoras de hipossuficiência econômica tenham acesso a assistência técnica pública e gratuita. Partindo dessa premissa, o curso de Engenharia Civil da UNIFESSPA, por meio da implantação de um Escritório Modelo, se propôs a atender as demandas sociais por projetos técnicos especializados na área de Engenharia Civil, permitindo que os discentes desenvolvessem as habilidade e competências de comunicar informações técnicas. Os problemas atendidos pelo Escritório Modelo eram estruturados com base em uma metodologia ativa de aprendizagem intitulada Project Based Learning (PBL), que permitia que eles, baseados nas informações técnicas disponibilizadas, elaborassem soluções para as demandas de projetos que o Escritório Modelo atendia. Durante o período de vigência do Escritório Modelo foram atendidos 20 projetos, de diversas áreas da Construção Civil, desde projetos de acessibilidade arquitetônica, como também, hierarquização de vias de transporte público coletivo. Um grande intermediador das demandas sociais foi a Prefeitura Municipal de Marabá, que passava pela revisão do Plano Diretor Municipal.

No sentido utilizado por Sobral (2000) para ensino propedêutico, enquanto aquele responsável pela preparação do discentes para as próximas fases do ensino, o Escritório Modelo se apresenta como uma ferramenta educacional para permear esses diálogos técnicos e sociais, com as aplicações práticas de conteúdo do currículo do curso, como também, para inserção dos temas transversais (Direitos Humanos, Meio Ambiente, Gênero e Diversidade, Acessibilidade, etc.). Para evidenciar isso, este trabalho se utiliza do relato de experiência para narrar as reflexões sobre os dois anos de existência do Escritório Modelo.

\section{METODOLOGIA}

Para realização desse estudo de adaptou o método apresentado por Kinalski et al. (2017), no tocante a definição do Grupo Focal de análise (20 discentes da disciplina de Topografia). Para a análise do desempenho educacional deles diante das proposições de demandas técnicas, que foram respondidas em forma de projeto, foi adaptado o percurso etnográfico exposto por Michel et al. (2013). Dessa maneira, o Grupo Focal era arguido em relação ao problema proposto: 1) Quais conhecimentos eram necessários para 
resolução do mesmo?; 2) Quais atividades deveriam realizar para concluir a demanda?; 3) Quais métricas poderiam ser adotadas para aceitar os resultados?; 4) Quem seria responsável por cada atividade?; e 5) Qual seria o produto final?.

Seguindo o método adotado por Michel et al. (2013), a coleta de informações se deu de maneira observacional, formulando hipóteses com base nas respostas dos discentes aos questionamentos supracitados. Tais hipóteses poderiam porventura serem aprofundadas com mais entrevistas e observações, conforme um padrão cíclico, característico do método etnográfico (SPRADLEY, 1980). Essas hipóteses eram: 1) Os discentes estão utilizando conteúdo das disciplinas do núcleo básico do curso na solução de problemas; 2) Os discentes percebem que estão utilizando conteúdo das disciplinas básicas do curso; e 3) Na visão dos discentes eles estão contribuindo para demandas sociais.

Com base no exposto, foi elaborado o relato de experiência das atividades do Escritório Modelo, no caso da demanda por um projeto de adequação de passeio público.

\section{RESULTADOS E DISCUSSÃO}

Na primeira reunião com o Grupo Focal, pode-se perceber um estranhamento inicial quanto a proposta metodológica, uma vez que, diversos questionamentos foram feitos por parte dos discentes, principalmente referente a forma como eles fariam para desenvolver o trabalho, visto que, eles não tinham os conhecimentos necessários para atender a demanda. Essa observação foi baseada nas falas que em comum, expressavam dúvidas sobre como executar o serviço.

Considerando o histórico do curso de Engenharia Civil, os discentes, em geral, experimentavam o contato com as informações dos conteúdos por meio de aulas expositivas, onde após os conceitos serem expostos, problemas que aplicavam esses conceitos eram propostos e resolvidos, e os discentes replicavam isso em problemas similares. A inversão disso, eles tendo que primeiramente ter contato com o problema, buscar informações, e testá-las, até então era um percurso novo. Essa aflição estava presente em suas falas, como por exemplo: 'como vamos fazer esse trabalho, se nunca fizemos antes?'.

Parte dos trabalhos de Engenharia Civil, são projetos, e conforme apregoa o PMI (2013) a característica intrínseca de um projeto é não ter sido desenvolvido antes. Dessa maneira, no decorrer de suas atividades profissionais, o Grupo Focal irá se deparar-se com atividades que não realizaram antes, e deverão desenvolver estratégias para conseguir realizá-las.

Passado o estranhamento inicial com a mudança de percurso de ensino, os discentes se organizaram em grupos, por julgarem que a atividade tornar-se-ia mais 'fácil' e executável se eles dividissem em tarefas entre grupos. Nesse momento, se verificava a aplicação de conteúdos de Introdução à Engenharia Civil, os quais seriam aprofundados nos semestres vindouros do curso. Entretanto, conforme eles iam organizando a demanda em tarefas menores, questionavam se não existiria 'métodos' para organizar essas tarefas (as ferramentas que eles demandavam são alvos dos conteúdos da disciplina 'Noções de Administração para Engenheiros'). Esse momento aproveitou-se para começar a arguição sobre: 1) Quais conhecimentos eram necessários para resolução do mesmo?; 2) Quais atividades deveriam realizar para concluir a demanda?; 3) 
Quais métricas poderiam ser adotadas para aceitar os resultados?; 4) Quem seria responsável por cada atividade?; e 5) Qual seria o produto final?.

Conforme eles organizavam suas demandas, rememoram que na disciplina de Introdução à Engenharia era apresentado para eles as áreas de Concentração do Curso, e suas respectivas atividades. E concluíram que lá, poderiam encontrar 'onde ir buscar as informações que precisavam'. A solução da demanda versava sobre realização de medidas, por meio de diastímetro, de um passeio público de 5 metros de extensão, e elaboração de proposta de adequação perante a Norma Brasileira Regulamentadora $9050 / 2015$.

Foi possível verificar no decorrer da execução do projeto, que eles conseguiam visualizar a aplicação de disciplinas do núcleo básico do curso, como: Desenho Técnico, Comunicação e Expressão, Direito e Legislação, Cálculo e Geometria Analítica, dentre outras. Conforme suas falas, durante a apresentação do projeto, que seria encaminhado a municipalidade, foi percebido o quanto eles julgavam importante que tais 'critérios' estivessem presentes no Plano Diretor Municipal (o qual se encontrava em revisão na época da atividade). Eles resolveram participar das audiências públicas, para verificar se as demandas levantadas por eles, tinham previsão de atendimento no Plano Diretor que estava sendo proposto.

A experiência permitiu verificar também um maior incremento da fixação dos conceitos de metodologia científica, como também, foi percebido que no decorrer de outros períodos, o Grupo Focal de Análise, apresentou mais de $50 \%$ de seus membros envolvidos em atividades de pesquisa e extensão, e grande parte correlacionou direta ou indiretamente as atividades práticas desenvolvidas como estímulo para essa conduta desde o início do curso.

Durante os diálogos necessários para acompanhamentos das demandas projetivas, foi possível realizar diálogos sobe os ditos temas transversais (Educação Ambiental, Cidadania, Gênero e Diversidade, Acessibilidade e Direitos Humanos), inclusive, com exemplificações da presença deles nas soluções projetivas. Esse fato foi deveras proveito, uma vez que, é muito narrado a dificuldade de correlacionar esses temas, com o ensino de conteúdo específicos do curso, ao menos, é a experiência vivenciada na instituição de ensino onde essa pesquisa foi desenvolvida.

\section{CONCLUSÕES}

A experiência desenvolvida pelo Escritório Modelo permitiu perceber que, os discentes, poderiam vivenciar outras formas de aprendizado além das tradicionalmente utilizadas nos cursos de Engenharia Civil (aula expositiva). Por meio da aplicação da metodologia ativa de aprendizagem foi possível, além de fomentar um ambiente educacional voltado para um propedêutica na Engenharia Civil, permitia que eles percebessem a importância de seus conhecimentos técnicos para construção de propostas de solução para dilemas sociais urbanos.

Dessa maneira, a atividade extensionista do Escritório Modelo permitiu não apenas atender demandas técnicas da sociedade, ou mesmo a realização de pesquisa sobre métodos de ensino em engenharia civil, mas possibilitou uma formação cidadã mais próxima das premissas das Diretrizes Nacionais 
para os Cursos de Engenharia, como também, o estímulo ao desenvolvimento de uma postura de investigação científica nos discentes envolvidos, desde os primeiros períodos do curso.

\section{REFERÊNCIAS}

BECKER, B. K.. A urbe amazônida: a floresta e a cidade. Rio de Janeiro: Garamond, 2013.

BIBAS, L.; CARDOSO, A. C.. Redesenhos para Marabá/PA: aspectos socioambientais e desenho urbano. Arquitextos, v.17, 2016.

FEITOSA, T. S.; NASCIMENTO, A. C. S.; MARTINS, T. C.. Contribuições ao estudo da produção do espaço urbano: mobilidade descendente espacial na cidade de Marabá/PA. In: ENCONTRO NACIONAL DE TECNOLOGIA DO AMBIENTE CONSTRUÍDO: DESAFIOS E PERSPECTIVAS DA INTERNACIONALIZAÇÃO DA CONSTRUÇÃO, 16. Anais. São Paulo: ANTAC, 2016. p.5117-5130.

KINALSKI, D. D. F.; PAULA, C. C.; PADOIN, S. M. M.; NEVES, E. T.; KLEINUBING, R. E.; CORTES, L. F.. Grupo focal na pesquisa qualitativa: relato de experiência. Rev. Bras.

Enferm., Brasília, v.70, n.2, p.424-429. DOI:

http://dx.doi.org/10.1590/0034-7167-2016-0091
MICHEL, T.; LENARDT, M. H.. O trabalho de campo etnográfico em instituição de longa permanência para idosos. Esc. Anna Nery, Rio de Janeiro, v.17, n.2, p.375-380, 2013. DOI: http://dx.doi.org/10.1590/S141481452013000200024

PMI. Project Management Institute. A Guide to the Project Management Body of Knowledge (PMBOK Guide). Newton Square: PMI, 2013.

SOBRAL, F. A. F.. Educação para concorrência ou cidadania social?. São Paulo Perspec., São Paulo, v.14, n.1, p.3-11, 2000. DOI: http://dx.doi.org/10.1590/S010288392000000100002

SPRADLEY, J. P.. Participant observation. Orlando: Holt, Rinehart and Winston, 1980.

A CBPC - Companhia Brasileira de Produção Científica (CNPJ: 11.221.422/0001-03) detém os direitos materiais desta publicação. Os direitos referem-se à publicação do trabalho em qualquer parte do mundo, incluindo os direitos às renovações, expansões e disseminações da contribuição, bem como outros direitos subsidiários. Todos os trabalhos publicados eletronicamente poderão posteriormente ser publicados em coletâneas impressas sob coordenação da Sapientiae Publishing, da Companhia Brasileira de Produção Científica e seus parceiros autorizados. Os (as) autores (as) preservam os direitos autorais, mas não têm permissão para a publicação da contribuição em outro meio, impresso ou digital, em português ou em tradução. 